Article

\title{
Formation of Bifunctional Octasilsesquioxanes via Silylative Coupling and Cross-Metathesis Reaction ${ }^{\dagger}$
}

\author{
Małgorzata Bołt ${ }^{1}$, Patrycja Żak ${ }^{1, *(\mathbb{D})}$, Beata Dudziec ${ }^{1,2, *}{ }^{\mathbb{D}}$, Anna Schulmann ${ }^{1}$ and \\ Bogdan Marciniec ${ }^{2}$ \\ 1 Department of Organometallic Chemistry, Faculty of Chemistry, Adam Mickiewicz University in Poznan, \\ Uniwersytetu Poznańskiego 8, 61-614 Poznan, Poland; malgorzata.bolt@amu.edu.pl (M.B.); \\ anna.schulmann@amu.edu.pl (A.S.) \\ 2 Centre for Advanced Technologies, Adam Mickiewicz University in Poznan, Uniwersytetu Poznańskiego 10, \\ 61-614 Poznan, Poland; bogdan.marciniec@amu.edu.pl \\ * $\quad$ Correspondence: pkw@amu.edu.pl (P.Ż.); beata.dudziec@gmail.com (B.D.); Tel.: +48-61-829-17-31 (P.Ż.); \\ +48-61-829-18-78 (B.D.) \\ + Dedicated to Professor Bronislaw Marciniak on the occasion of his 70th birthday.
}

Received: 23 July 2020; Accepted: 6 September 2020; Published: 8 September 2020

check for updates

\begin{abstract}
Bifunctional silsesquioxanes create an attractive group of compounds with a wide range of potential applications, and recently they have gained much interest. They are known to be obtained mainly via hydrosilylation, but we disclose novel synthetic protocols based on different but complementary reactions, i.e., cross-metathesis (CM) and silylative coupling (SC). A series of cubic $\mathrm{T}_{8}$ type silsesquioxane derivatives with a broad scope of styryl substituents were synthesized in a one-pot procedure and characterized by spectroscopic and spectrometric methods. All of the new compounds can be obtained in a one-pot manner, which has an attractive impact on the synthetic procedure, as it is economic in terms of the isolation of intermediate products. Additionally, the methodology disclosed here enables the $(E)$-stereoselective introduction of styrenes derivative to the cubic $\mathrm{T}_{8}$ type core. The presented compounds can be interesting precursors for a further functionalization that may significantly increase the possibility of their application in the design and synthesis of new functional materials.
\end{abstract}

Keywords: silsesquioxanes; bifunctional silsesquioxanes; cross-metathesis; silylative coupling; catalysis

\section{Introduction}

Polyhedral oligosilsesquioxanes with the general formula $\left(\mathrm{RSiO}_{3 / 2}\right)_{n}$ are currently one of the most attractive organosilicon compounds [1,2]. Among many advantages of these compounds, i.e., exclusive properties derived from a chemically and thermally robust organic-inorganic framework, and tailor-made three-dimensional structures, the ease of their modification by many synthetic methods is of the utmost importance. The simple functionalization of the inorganic core, as well as of the organic moieties attached to it, allows one to create various structures and to control the properties of the obtained materials. Among the highly valuable synthetic procedures for the functionalization of silsesquioxanes (SQs), we can list Heck coupling [3-5], Sonogashira coupling [6], hydrosilylation [7-15], cross-metathesis (CM) [16-19], silylative coupling (SC) [20], O-silylation [21,22] and Friedel-Crafts [23]. They are all dependent on the type of the functional group attached to the $\mathrm{Si}-\mathrm{O}-\mathrm{Si}\left(\mathrm{SiHC}=\mathrm{CH}_{2}, \mathrm{SiH} \mathrm{SiOH}\right)$. The utilization of these multiple protocols provides a wide range of inorganic/organic hybrid systems that find great application potential in material chemistry, optics, electronics, and catalysis, as well as in medical science [2,24-26]. 
Among the many different types of silsesquioxanes, the cubic $\mathrm{T}_{8}$ group of molecules has still been the most common in research. Lately, special interest has shifted towards silsesquioxanes with mixes of functional groups connected to the inorganic core. The presence of different organic/organometallic moieties anchored onto the $\mathrm{Si}-\mathrm{O}-\mathrm{Si}$ core opens possibilities for the formation of a novel generation of SQs-based systems with a simultaneous control of their properties, resulting from the type and number of functional groups. In 1996, Sellinger and Laine performed a hydrosilylation reaction on both $\left(\mathrm{HSiO}_{3 / 2}\right)_{8}$ and $\left(\mathrm{HMe}_{2} \mathrm{SiOSiO}_{3 / 2}\right)_{8}$ with four equivalents of methacrylate, leaving four core hydrogen atoms unreacted [27]. Since then, some different attempts have been made to find an effective path for multifunctional SQ's synthesis. However, the reports on this are still limited in the literature. Nevertheless, hydrosilylation remains one of the most useful methods for obtaining bifunctional silsesquioxanes, and it has been the subject of multiple research papers $[7,8,10,12]$. Heck coupling [28-31] and condensation reactions [32-36] were also applied in this type of synthesis. There are also single notes on the utilization of thiol-ene [37], hydration [38,39] and click type reactions [40-42] for the synthesis of multifunctionalized silsesquioxanes. As stated, bifunctional SQ's derivatives, due to the presence of different functionalities in the same core, possess a high application potential, e.g., as hydrophobic materials [43-46], mold material for nanoimprint lithography [47], anion sensors [31,48], Janus star polymers [49,50] or platforms for anchoring and delivering biologically active compounds in biomedicine [51]. Bifunctional silsesquioxanes with a $T_{8} R_{4} R_{4}^{\prime}$ formula are of particular scientific interest because it was demonstrated that they can be considered to be Janus-type molecules [52]. However, all of these procedures lead to the formation of a mixture of products with functional groups statistically distributed on the SQ cage, and maintaining control of this process remains barely possible. The isolation of a respective product may also be complicated and not always possible. Among these synthetic protocols elaborated to obtain bifunctional SQs, the reports on the application of silylative coupling [53] to yield these compounds are still very scanty, and there is no information on the utilization of cross-metathesis and silylative coupling. These two universal and efficient functionalization methods have been developed earlier in our group and can be successfully applied in the synthesis of molecular and macromolecular silsesquioxane-based compounds $[17,18,20,54,55]$. Their mechanisms are slightly different, but both of them to generally lead to the same main products.

Herein, we report on the efficient and selective bifunctionalization of octa(vinyl)silsesquioxanes (OVS- $\mathrm{CH}_{2}=\mathrm{CH}-{ }_{8} \mathrm{Si}_{8} \mathrm{O}_{12}$ ) and octakis(dimethylvinylsilyloxy)silsesquioxane $\left(\mathrm{Q}_{8} \mathrm{M}_{8}-\left(\mathrm{CH}_{2}=\mathrm{CH}-\mathrm{SiMe}_{2}-\right)_{8} \mathrm{Si}_{8} \mathrm{O}_{12}\right)$ via cross-metathesis and silylative coupling processes with styrene derivatives. We decided to show the aspects of the synthetic procedures using respective Ru-based catalytic systems for the formation of the desired products. Additionally, the details of the processes affecting the distribution of the introduced functional groups in the obtained compounds were verified. Finally, the aim of this report was the efficient synthesis of novel silsesquioxanes with mixed functionalities in the course of a one-pot procedure, which was also a unique synthetic approach in the case of cross-metathesis and an innovation for silylative coupling and cubic $\mathrm{T}_{8}$ type SQs (Figure 1).

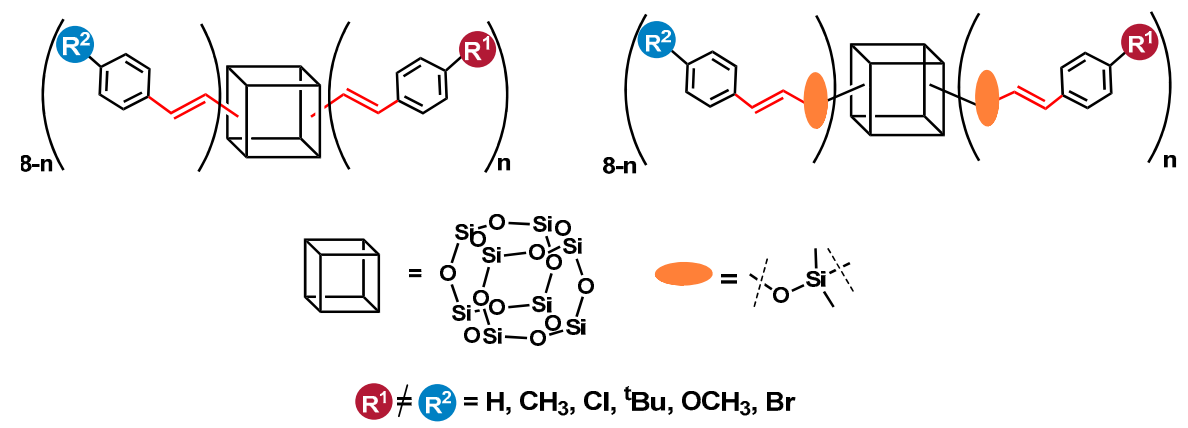

Figure 1. Silsesquioxanes with mixed functional groups obtained in this work. 
We intended to obtain a spectrum of SQ derivatives with various styryl moieties, especially with unreactive and reactive $R_{1}, R_{2}$ groups, enabling their further modifications.

\section{Materials and Methods}

\subsection{Materials}

The chemicals were obtained from the following sources: styrene, 4-chlorostyrene, 4-methoxystyrene, 4-bromostyrene, 4-methylstyrene, 4-tert-butylstyrene, dichloromethane, chloroform-d, copper(I) chloride, anhydrous magnesium sulphate, calcium hydride, silica gel $60 \AA$, Celite ${ }^{\circledR}$ from Aldrich (Sigma-Aldrich, St. Louis, MO, USA), toluene, acetone, n-hexane from Chempur, octavinylsilsesquioxane (OVS) and octakis(dimethylvinylsilyloxy)silsesquioxane $\left(\left(\mathrm{ViSiMe}_{2} \mathrm{O}\right)_{8} \mathrm{Si}_{8} \mathrm{O}_{12}\right)$ from Hybrid Plastics (Hattiesburg, MS, USA), first-generation Grubbs' catalyst from Apeiron Synthesis. $\left[\mathrm{RuHCl}(\mathrm{CO})(\mathrm{SIDip})\left(\mathrm{PCy}_{3}\right)\right]$ was prepared according to the literature procedure [56]. All solvents were dried prior to use over $\mathrm{CaH}_{2}$ and stored under argon. $\mathrm{CH}_{2} \mathrm{Cl}_{2}$ was additionally passed through a column with alumina, and then it was degassed by repeated freeze-pump-thaw cycles. Unless mentioned otherwise, all operations were performed by using standard Schlenk techniques.

\subsection{Nuclear Magnetic Resonance Spectroscopy (NMR)}

${ }^{1} \mathrm{H},{ }^{13} \mathrm{C}$ NMR and ${ }^{29} \mathrm{Si}$ NMR spectra were recorded on Bruker Ultra Shield 600 (Faellanden, Switzerland) operating at 400, 100 and $79 \mathrm{MHz}$, respectively. $\mathrm{CDCl}_{3}$ was used as a solvent in all measurements. The chemical shifts are reported in $\mathrm{ppm}$, referenced to the residual solvent signal $\left(\mathrm{CDCl}_{3}\right)$.

\subsection{Matrix-Assisted Ultraviolet Laser Desorption/Ionization Time-of-Flight Mass Spectroscopy (MALDI-TOF-MS)}

MALDI-TOF mass spectra were recorded on a UltrafleXtreme mass spectrometer (Bruker Daltonics, Bremen, Germany), equipped with a SmartBeam II laser $(355 \mathrm{~nm})$ in the $500-4000 \mathrm{~m} / \mathrm{z}$ range. 2,5-Dihydroxybenzoic acid (DHB, Bruker Daltonics, Bremen, Germany) served as the matrix and was prepared in TA30 solvent (30:70 $v / v$ acetonitrile: $0.1 \%$ TFA in water) at a concentration of $20 \mathrm{mg} / \mathrm{mL}$. The studied samples were dissolved in dichloromethane $(2 \mathrm{mg} / \mathrm{mL})$ and then mixed in a ratio $1: 1 \mathrm{v} / \mathrm{v}$ with a matrix solution. The matrix/sample mixtures $(1 \mu \mathrm{L})$ were spotted onto the MALDI target and dried in air. The mass spectra were measured in reflection mode. The data were analyzed using the software provided with the Ultraflex instrument-FlexAnalysis (version 3.4). The mass calibration (cubic calibration based on five to seven points) was performed using external standards (Peptide Calibration Standard).

\subsection{FT-IR Spectroscopy}

Fourier Transform-Infrared (FT-IR) spectra were recorded on a Nicolet iS5 (Thermo Scientific, Waltham, MA, USA) spectrophotometer equipped with a diamond ATR unit. In all cases, 16 scans at a resolution of $2 \mathrm{~cm}^{-1}$ were collected to record the spectra in a range of $4000-650 \mathrm{~cm}^{-1}$.

\subsection{Synthesis of Bifunctional Silsesquioxanes via Cross-Metathesis}

A 5-mL glass reactor equipped with a reflux condenser and connected to an argon/vaccum line was charged with octavinylsilsesquioxane $\left(0.1 \mathrm{~g}, 1.6 \times 10^{-4} \mathrm{~mol}\right), \mathrm{CH}_{2} \mathrm{Cl}_{2}(3 \mathrm{~mL})$ and styrene or 4-substituted styrene $\left(\mathrm{n} \times 1.6 \times 10^{-4} \mathrm{~mol}\right.$, the amounts depend on the required silsesquioxane: olefin molar ratio). The mixture was warmed up to $45^{\circ} \mathrm{C}$ in an oil bath, and a first-generation Grubbs' catalyst $\left(\mathrm{n} \times 1.6 \times 10^{-6} \mathrm{~mol}\right)$ was added under argon. The reaction mixture was heated under reflux until a full conversion of the substrates was detected by Thin Layer Chromatography (TLC) (typically 6-9 h depending on the styrene used). Next, the solvent was evaporated under vacuum, and cold methanol $(2 \mathrm{~mL})$ was added to the remains to form a white precipitate. The precipitate was filtered 
off, dissolved in hexane and purified by column chromatography (Silica Gel, $n$-hexane/DCM = 9:1) to remove traces of ruthenium complexes. The evaporation of the solvent gave an analytically pure sample (white powder). The isolated product was then analyzed and used for the next functionalization with a different type of styrene. The reaction and isolation conditions remained the same.

\subsection{Synthesis of Bifunctional Silsesquioxanes via Cross-Metathesis in a One-Pot Manner}

A 5-mL glass reactor equipped with a reflux condenser and connected to an argon/vacuum line was charged with octavinylsilsesquioxane $\left(0.1 \mathrm{~g}, 1.6 \times 10^{-4} \mathrm{~mol}\right), \mathrm{CH}_{2} \mathrm{Cl}_{2}(3 \mathrm{~mL})$ and the first type of styrene or 4-substituted styrene $\left(\mathrm{n} \times 1.6 \times 10^{-4} \mathrm{~mol}\right.$, the amounts depend on the required silsesquioxane: olefin molar ratio). The mixture was warmed up to $45^{\circ} \mathrm{C}$ in an oil bath, and a first-generation Grubbs' catalyst $\left(\mathrm{n} \times 1.6 \times 10^{-6} \mathrm{~mol}\right)$ was added under argon. The reaction mixture was heated under reflux until a full conversion of the substrates was detected by TLC (typically 6-9 $\mathrm{h}$ depending on the styrene used). After this time, the second type of styrene $\left((8-\mathrm{n}) \times 1.6 \times 10^{-4} \mathrm{~mol}\right)$ and the second portion of the catalyst $\left((8-\mathrm{n}) \times 1.6 \times 10^{-6} \mathrm{~mol}\right)$ was added. The reaction mixture was left for $15 \mathrm{~h}$. Next, the solvent was evaporated under vacuum, and cold methanol $(2 \mathrm{~mL})$ was added to the remains to form a white precipitate. The precipitate was filtered off, dissolved in hexane and purified by column chromatography (Silica Gel, $n$-hexane/DCM = 9:1, Fluka Chemie AG, Buchs, Switzerland) to remove traces of ruthenium complexes. The evaporation of the solvent gave an analytically pure sample (white powder).

\subsection{Synthesis of Bifunctional Silsesquioxanes via Silylative Coupling}

A 5-mL glass reactor equipped with a reflux condenser and connected to an argon/vacuum line was charged with octakis(dimethylvinylsilyloxy)silsesquioxane $\left(0.1 \mathrm{~g}, 1.6 \times 10^{-4} \mathrm{~mol}\right), \mathrm{CH}_{2} \mathrm{Cl}_{2}(3 \mathrm{~mL})$ and styrene or 4-substituted styrene $\left(\mathrm{n} \times 1.6 \times 10^{-4} \mathrm{~mol}\right.$, the amounts depend on the required silsesquioxane: olefin molar ratio). The mixture was warmed up to $45^{\circ} \mathrm{C}$ in an oil bath, and [RuHCl (CO)(SIDip)(PCy $)$ ] $\left(\mathrm{n} \times 1.6 \times 10^{-6} \mathrm{~mol}\right)$ was added under argon. After $5 \mathrm{~min}, \mathrm{CuCl}\left(5 \times \mathrm{n} \times 1.6 \times 10^{-6} \mathrm{~mol}\right)$ was added to the reactor as a cocatalyst. The reaction mixture was heated under reflux until a full conversion of the substrates was detected by TLC (typically 6-9 h depending on the styrene used, Sigma-Aldrich, St. Louis, MO, USA). Next, the solvent was evaporated under vacuum, and cold methanol $(2 \mathrm{~mL})$ was added to the remains to form a white precipitate. The precipitate was filtered off, dissolved in hexane and purified by column chromatography (Silica Gel, $n$-hexane/DCM $=9: 1$ ) to remove traces of ruthenium complexes. The evaporation of the solvent gave an analytically pure sample (white powder). The isolated product was then analyzed and used for the next functionalization with a different type of styrene. The reaction and isolation conditions remained the same.

\subsection{Synthesis of Bifunctional Silsesquioxanes via Silylative Coupling in a One-Pot Manner}

A 5-mL glass reactor equipped with a reflux condenser and connected to an argon/vacuum line was charged with octakis(dimethylvinylsilyloxy)silsesquioxane $\left(0.1 \mathrm{~g}, 1.6 \times 10^{-4} \mathrm{~mol}\right), \mathrm{CH}_{2} \mathrm{Cl}_{2}(3 \mathrm{~mL})$ and the first type of styrene or 4-substituted styrene $\left(\mathrm{n} \times 1.6 \times 10^{-4} \mathrm{~mol}\right.$, the amounts depend on the required silsesquioxane: olefin molar ratio). The mixture was warmed up to $45^{\circ} \mathrm{C}$ in an oil bath, and $\left[\mathrm{RuHCl}(\mathrm{CO})(\mathrm{SIDip})\left(\mathrm{PCy}_{3}\right)\right]\left(\mathrm{n} \times 1.6 \times 10^{-6} \mathrm{~mol}\right)$ was added under argon. After $5 \mathrm{~min}, \mathrm{CuCl}$ $\left(5 \times \mathrm{n} \times 1.6 \times 10^{-6} \mathrm{~mol}\right)$ was added to the reactor as a cocatalyst. The reaction mixture was heated under reflux until a full conversion of the substrates was detected by TLC (typically 6-9 $\mathrm{h}$ depending on the styrene used). After this time, the second type of styrene $\left((8-\mathrm{n}) \times 1.6 \times 10^{-4} \mathrm{~mol}\right)$, catalyst $\left((8-\mathrm{n}) \times 1.6 \times 10^{-6} \mathrm{~mol}\right)$ and $\mathrm{CuCl}\left(5 \times(8-\mathrm{n}) \times 1.6 \times 10^{-6} \mathrm{~mol}\right)$ were added. The reaction mixture was left for $15 \mathrm{~h}$. Next, the solvent was evaporated under vacuum, and cold methanol ( $2 \mathrm{~mL})$ was added to the remains to form a white precipitate. The precipitate was filtered off, dissolved in hexane and purified by column chromatography (Silica Gel, $n$-hexane/DCM =9:1) to remove traces of ruthenium complexes. The evaporation of the solvent gave an analytically pure sample (white powder). 


\section{Results and Discussion}

\subsection{Functionalization of Octa(vinyl)silsesquioxanes (OVS) via Cross-Metathesis Reaction}

In the first step, we examined the possibility of obtaining a non-fully functionalized silsesquioxane core with one free vinyl group. Treatment of the 1 equiv. octavinylsilsesqioxane (OVS) with 7 equiv. of styrene (2a) in $\mathrm{CH}_{2} \mathrm{Cl}_{2}$ at $45^{\circ} \mathrm{C}$ in the presence of the first-generation Grubbs' catalyst gave rise to the slow evolution of ethylene and formation of heptasubstituted silsesquioxane ( $\left.3 \mathrm{a}_{7}\right)$ (Scheme 1).
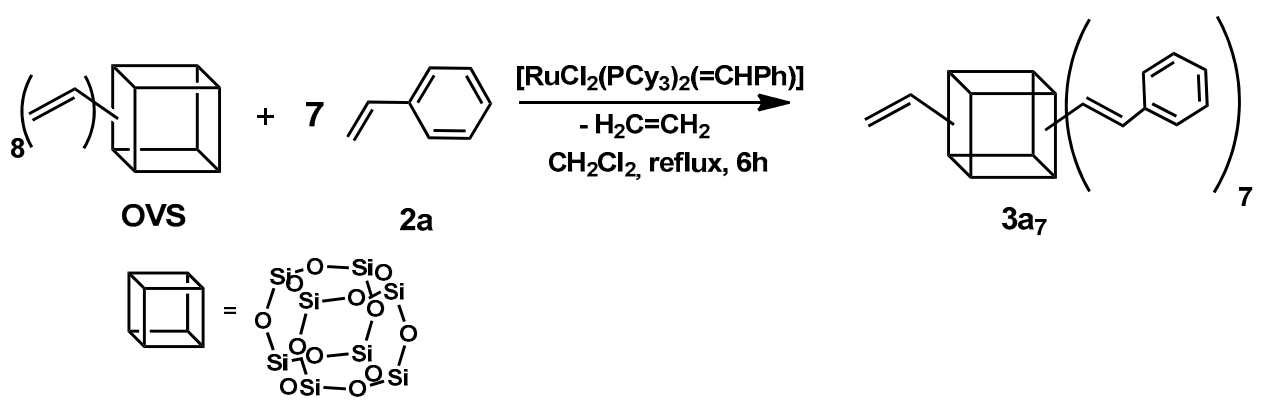

Scheme 1. The first step of the sequential cross-metathesis on octa(vinyl)silsesquioxanes.

The reaction progress was monitored by TLC, due to the large mass of the product eliminating the possibility of using GC or GC-MS. For all of the tested styrenes, a nearly complete conversion was observed up to $9 \mathrm{~h}$. In the ${ }^{1} \mathrm{H}$ NMR spectrum registered after this time, the only signals observed derived from a product $3 a_{7}$ corresponding to the presence of seven ethenyl moieties and one vinyl group in the molecule. The protons from ethenyl and the free vinyl group gave only one multiplet in the range between 6.10 and 6.38 ppm, which made it impossible to define the geometry of the newly formed double bonds (Scheme 1). However, in the case of octastyrylfunctionalized silsesquioxanes, the cross-metathesis was stereoselective towards the E-isomers [17].

To confirm the product's structure, we conducted a reaction between $3 a_{7}$ and one equivalent of 4-methylstyrene (2b). The analysis of the ${ }^{1} \mathrm{H}$ NMR spectrum revealed the presence of two separate doublets with ca. $J_{H-H}=19 \mathrm{~Hz}$. This result indicated the formation of a product with an $E$ geometry of newly formed double bonds, which stood in agreement with our earlier research [17,20]. It also confirmed the functionalization of the silsesquioxane core with two different styrenes in the 7:1 molar ratio (Scheme 2).

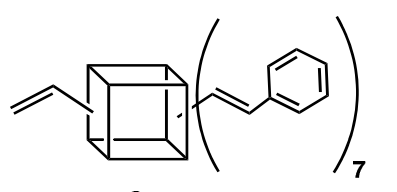

$3 \mathbf{a}_{7}$

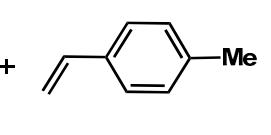

$2 \mathbf{b}$

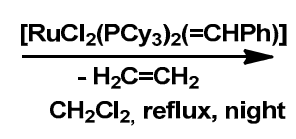

$\mathrm{CH}_{2} \mathrm{Cl}_{2}$, reflux, night

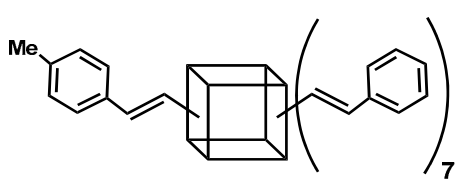

$\mathbf{4 a} \mathbf{a}_{7} \mathbf{b}$

Scheme 2. The second step of the sequential cross-metathesis on octa(vinyl)silsesquioxanes.

The MALDI-TOF analysis indicated the formation of a mixture of statistical substitution $\left(\mathrm{Me}-\mathrm{C}_{6} \mathrm{H}_{4}-\mathrm{CH}=\mathrm{CH}-\right)_{8-\mathrm{n}}\left(\mathrm{C}_{6} \mathrm{H}_{5}-\mathrm{CH}=\mathrm{CH}-\right)_{\mathrm{n}} \mathrm{Si}_{8} \mathrm{O}_{12}$ (where $\left.\mathrm{n}=8,7,6,5,4\right)$ and the presence of respectively functionalized compounds at a ratio of 23:40:26:9:2, with a predominance of the desired compound $4 \mathrm{a}_{7} \mathrm{~b}\left(\mathrm{Me}-\mathrm{C}_{6} \mathrm{H}_{4}-\mathrm{CH}=\mathrm{CH}-\right)_{8-\mathrm{n}}\left(\mathrm{C}_{6} \mathrm{H}_{5}-\mathrm{CH}=\mathrm{CH}-\right)_{\mathrm{n}} \mathrm{Si}_{8} \mathrm{O}_{12}$ (where $\mathrm{n}=7$ ) (which can occur with different constitutional isomers) [52] (Figure 2). This result is also evidence of the statistical substitution in the case of $3 a_{7}$, where a complete substitution of vinyl groups could be observed ( $\left.3 a_{8}\right)$, which was also confirmed by MALDI-TOF. 

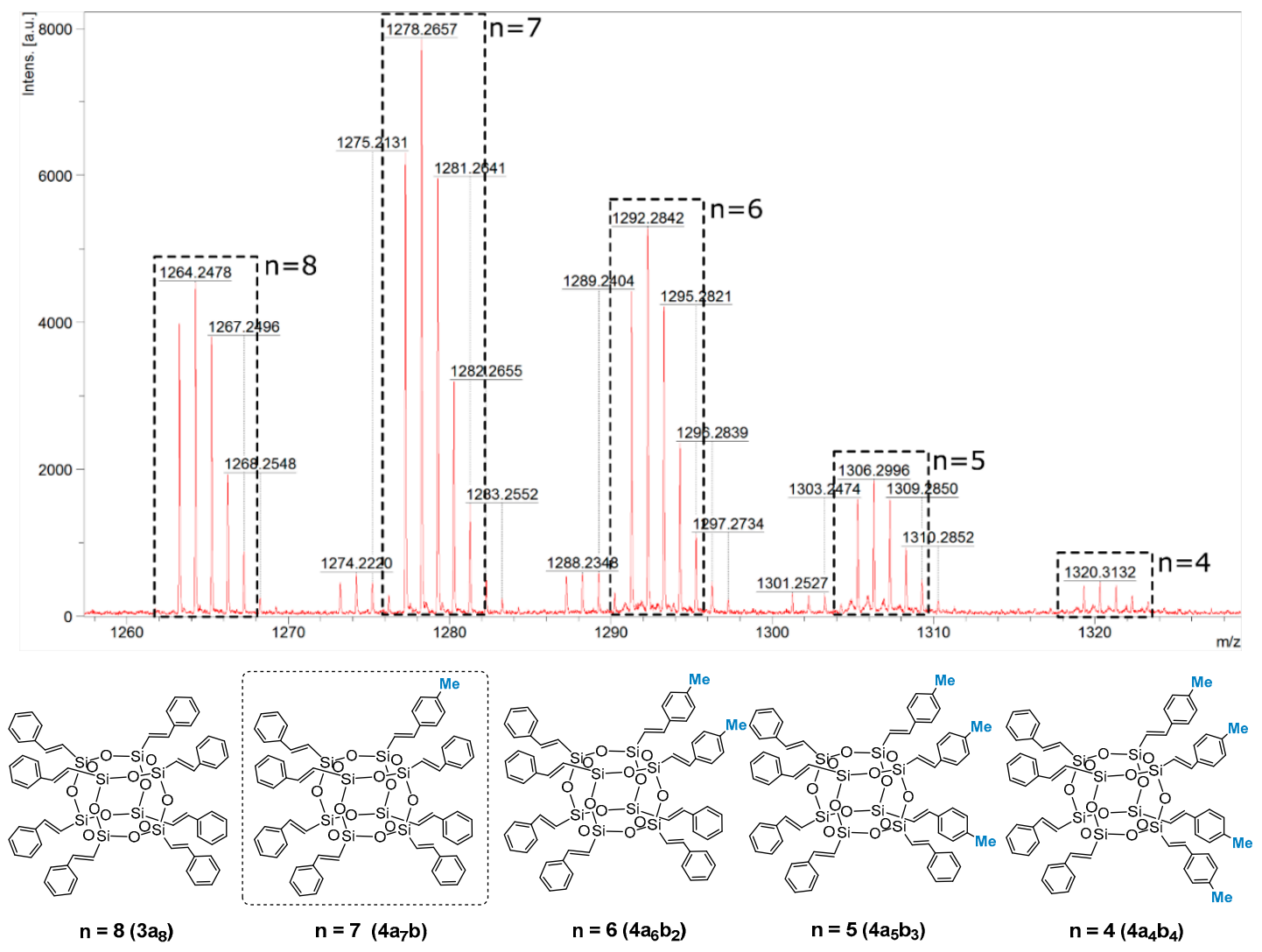

Figure 2. MALDI-TOF and structures with respective styrene substitutions present in the reaction mixture $\left(\mathrm{Me}-\mathrm{C}_{6} \mathrm{H}_{4}-\mathrm{CH}=\mathrm{CH}-\right)_{8-n}\left(\mathrm{C}_{6} \mathrm{H}_{5}-\mathrm{CH}=\mathrm{CH}-\right)_{n} \mathrm{Si}_{8} \mathrm{O}_{12}$ (where $\left.\mathrm{n}=8,7,6,5,4\right)$ with a predominance of the designated $4 a_{7} b$.

After the first positive results, we decided to apply a cross-metathesis reaction to the functionalization of the SQ core with different types of styrene derivatives. We also used different ratios of OVS and two types of styrenes to discover whether the stoichiometry changes were the only factor that might affect the control of the reaction products. In all cases, the nuclear magnetic resonance analysis confirmed the exclusive formation of the desired product with an $E$-geometry of the $\mathrm{C}=\mathrm{C}$ bond. It is worth mentioning that the reaction can be conducted in two different ways: with the isolation of the first substitution product $3\left(\mathrm{CH}_{2}=\mathrm{CH}-\right)_{8-n}\left(\mathrm{R}^{1} \mathrm{C}_{6} \mathrm{H}_{5}-\mathrm{CH}=\mathrm{CH}-\right)_{n} \mathrm{Si}_{8} \mathrm{O}_{12}$, or in a one-pot manner that leads directly towards obtaining the product $\left.4 \mathrm{R}^{2}-\mathrm{C}_{6} \mathrm{H}_{4}-\mathrm{CH}=\mathrm{CH}-\right)_{8-n}\left(\mathrm{R}^{1}-\mathrm{C}_{6} \mathrm{H}_{4}-\mathrm{CH}=\mathrm{CH}-{ }_{n} \mathrm{Si}_{8} \mathrm{O}_{12}\right.$, without isolation. In this way, the second type of styrene derivative and the next portion of the catalyst was added after 6-9 $\mathrm{h}$, and the process was maintained for the next $15 \mathrm{~h}$ (Scheme 3).

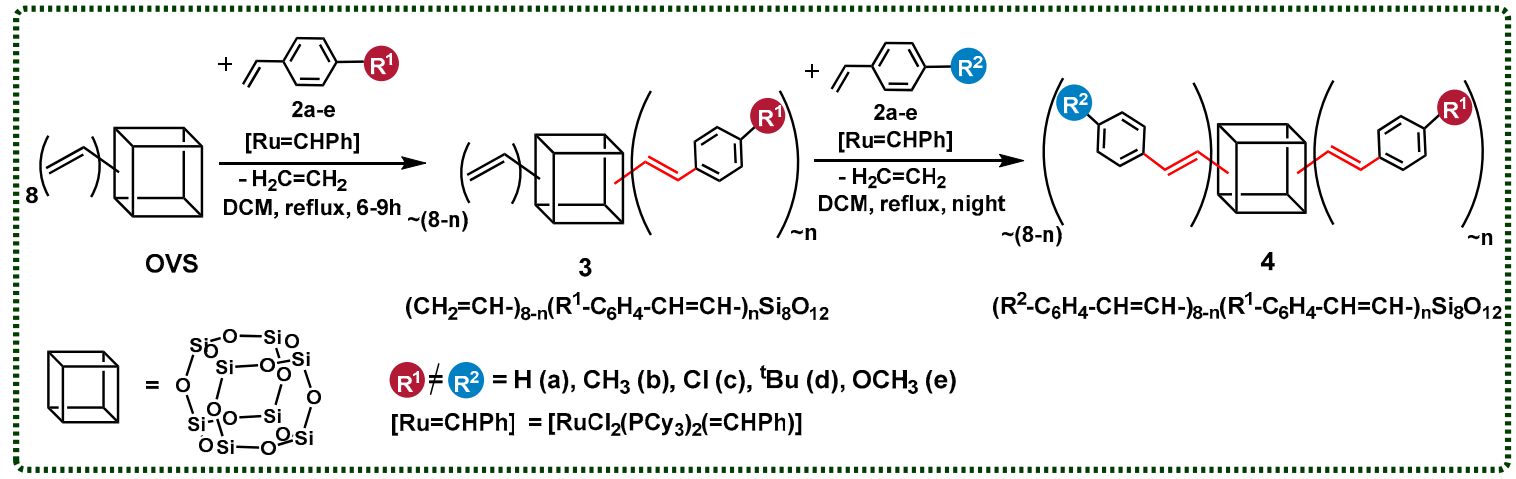

Scheme 3. Cont. 


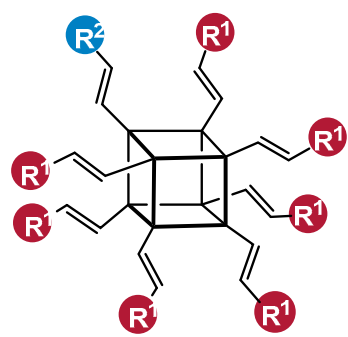

$\mathrm{n}=7 ; \mathbf{3} \mathbf{a}_{\sim 7} \quad \mathrm{R}^{1}=\mathrm{C}_{6} \mathrm{H}_{5}, \mathrm{R}^{2}=\mathrm{H}$

$\mathrm{n}=7 ; \mathbf{4} \mathbf{a}_{\sim} \mathbf{7} \mathbf{b}_{\sim 1} \mathrm{R}^{1}=\mathrm{C}_{6} \mathrm{H}_{5}, \mathrm{R}^{2}=\mathrm{C}_{6} \mathrm{H}_{4}-\mathrm{Me}$

$\mathrm{n}=7 ; \mathbf{4} \mathbf{a}_{\sim 7} \mathbf{c}_{\sim 1} \mathrm{R}^{1}=\mathrm{C}_{6} \mathrm{H}_{5}, \mathrm{R}^{2}=\mathrm{C}_{6} \mathrm{H}_{4}-\mathrm{Cl}$

$\mathrm{n}=7 ; \mathbf{4} \mathbf{a}_{\sim 7} \mathbf{d}_{\sim 1} \mathrm{R}^{1}=\mathrm{C}_{6} \mathrm{H}_{5}, \mathrm{R}^{2}=\mathrm{C}_{6} \mathrm{H}_{4^{-}}{ }^{\mathrm{t}} \mathrm{Bu}$

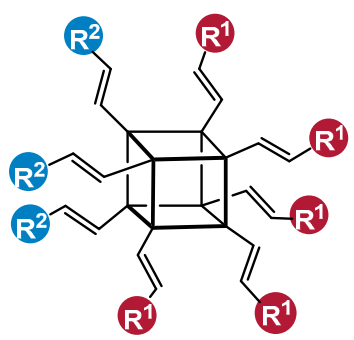

$\mathrm{n}=5 ; 3 \mathrm{c}_{\sim 5} \quad \mathrm{R}^{1}=\mathrm{C}_{6} \mathrm{H}_{4}-\mathrm{Cl}, \mathrm{R}^{2}=\mathrm{H}$

$\mathrm{n}=5 ; \mathbf{4} \mathbf{c}_{\sim 5} \mathbf{b}_{\sim 3} \mathrm{R}^{1}=\mathrm{C}_{6} \mathrm{H}_{4}-\mathrm{Cl}, \mathrm{R}^{2}=\mathrm{C}_{6} \mathrm{H}_{4}-\mathrm{Me}$

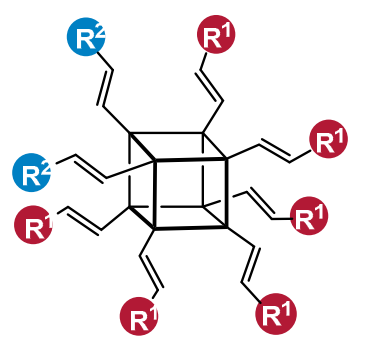

$\mathrm{n}=6 ; 3 \mathrm{~d}_{\sim 6} \quad \mathrm{R}^{1}=\mathrm{C}_{6} \mathrm{H}_{4}{ }^{-}{ }^{\mathrm{B}} \mathrm{Bu}, \mathrm{R}^{2}=\mathrm{H}$ $\mathrm{n}=6 ; \mathbf{4} \mathbf{d}_{\sim \mathbf{6}} \mathbf{a}_{\sim \mathbf{2}} \mathrm{R}^{1}=\mathrm{C}_{6} \mathrm{H}_{4}{ }^{-} \mathrm{B} \mathrm{Bu}, \mathrm{R}^{2}=\mathrm{C}_{6} \mathrm{H}_{5}$ $\mathrm{n}=6 ; \mathbf{4} \mathbf{d}_{\sim_{6} \mathbf{b}_{\sim 2}} \mathrm{R}^{1}=\mathrm{C}_{6} \mathrm{H}_{4}{ }^{-} \mathrm{B}, \mathrm{Bu}, \mathrm{R}^{2}=\mathrm{C}_{6} \mathrm{H}_{4}-\mathrm{Me}$ $\mathrm{n}=6 ; \mathbf{4} \mathbf{d}_{\sim 6} \mathbf{c}_{\sim 2} \mathrm{R}^{1}=\mathrm{C}_{6} \mathrm{H}_{4}{ }^{-}{ }^{\mathrm{t}} \mathrm{Bu}, \mathrm{R}^{2}=\mathrm{C}_{6} \mathrm{H}_{4}-\mathrm{Cl}$

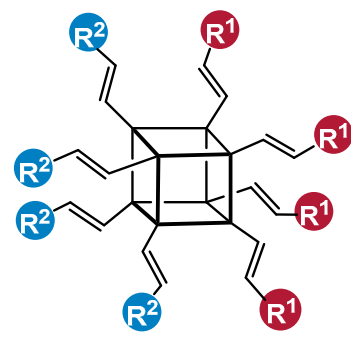

$\mathrm{n}=4 ; 3 \mathbf{b}_{\sim 4} \quad \mathrm{R}^{1}=\mathrm{C}_{6} \mathrm{H}_{4}-\mathrm{Me}, \mathrm{R}^{2}=\mathrm{H}$

$\mathrm{n}=\mathbf{4} ; \mathbf{4} \mathbf{b}_{\sim \mathbf{4}} \mathbf{a}_{\mathbf{4}} \mathrm{R}^{1}=\mathrm{C}_{6} \mathrm{H}_{4}-\mathrm{Me}, \mathrm{R}^{2}=\mathrm{C}_{6} \mathrm{H}_{5}$

$\mathrm{n}=\mathbf{4} ; \mathbf{4} \mathbf{b}_{\sim \mathbf{4}} \mathbf{e}_{\sim \mathbf{4}} \mathrm{R}^{1}=\mathrm{C}_{6} \mathrm{H}_{4}-\mathrm{Me}, \mathrm{R}^{2}=\mathrm{C}_{6} \mathrm{H}_{4}-\mathrm{OMe}$

Scheme 3. Two-step functionalization of octa(vinyl)silsesquioxane via cross-metathesis, resulting in the formation of $3\left(\mathrm{CH}_{2}=\mathrm{CH}-\right)_{8-n}\left(\mathrm{R}^{1} \mathrm{C}_{6} \mathrm{H}_{5}-\mathrm{CH}=\mathrm{CH}-\right)_{n} \mathrm{Si}_{8} \mathrm{O}_{12}$ and 4 $\left(\left(\mathrm{R}^{2}-\mathrm{C}_{6} \mathrm{H}_{4}-\mathrm{CH}=\mathrm{CH}-\right)_{8-\mathrm{n}}\left(\mathrm{R}^{1}-\mathrm{C}_{6} \mathrm{H}_{4}-\mathrm{CH}=\mathrm{CH}-\right)_{\mathrm{n}} \mathrm{Si}_{8} \mathrm{O}_{12}\right)$. Reaction conditions: DCM, 1st generation Grubbs catalyst, $[\mathrm{Ru}]=1.00 \mathrm{~mol} \%$, reflux, argon. The molecules designed to be obtained by the reaction's stoichiometry are presented.

In all cases, the conversion of the initial OVS was estimated at $>99 \%$, which was proven by ${ }^{1} \mathrm{H}$ NMR analysis. The statistical substitution of two types of styrenes is observed in each reaction mixture sample, which is also consistent with the literature $[7,8,12]$. The respective MALDI-TOF analyses that were performed for each reaction sample revealed the presence of a signal assigned to the desired product (of the depicted stoichiometry—respectively abbreviated), accompanied by signals identified as the product of higher and lower values of the desired substitution. Herein, to clarify the results' demonstration, the products of the desired value of substitution (designated by the applied reagents' stoichiometry) were shown (Scheme 3). For clarity, one constitutional isomer is presented for each structure.

All of the products were fully characterized by NMR, which confirmed the formation of targeted silsesquioxanes. ${ }^{1} \mathrm{H},{ }^{13} \mathrm{C}$ and ${ }^{29} \mathrm{Si}$ NMR spectra of the isolated compounds are available in ESI. The analysis of the ${ }^{29} \mathrm{Si}$ NMR spectra reveals resonance lines that shifted towards a higher field when compared with the silsesquioxanes described before $[57,58]$. The reason for this is the presence of the $\mathrm{C}=\mathrm{C}$ double bond at the closest vicinity to the cage silicon atoms and its shielding effect for these atoms. The same was observed previously in the case of monovinylfunctionalized cubic silsesquioxanes $[17,20,57,58]$. We observed the same phenomena in the case of functionalized octaspherosilicates, described in the following section (for details, see ESI).

\subsection{Functionalization of Octakis(dimethylvinylsilyloxy)silsesquioxane $\left(Q_{8} M_{8}\right)$-Silylative Coupling}

One of the limitations of the cross-metathesis of vinylsilanes is that it cannot be applied to molecules with two methyl groups connected to the silicon atom. Thus, for the effective functionalization of octakis(dimethylvinylsilyloxy)silsesquioxane (ocatvinylspherosilicate) $\left(\left(\mathrm{CH}_{2}=\mathrm{CH}-\mathrm{SiMe}_{2}-\right)_{8} \mathrm{Si}_{8} \mathrm{O}_{12}\right)$, 
silylative coupling was applied as a functionalization method. The reactions were performed in the presence of an $\mathrm{NHC}$ ruthenium-hydride catalyst $\left[\mathrm{RuHCl}(\mathrm{CO})(\mathrm{SIDip})\left(\mathrm{PCy}_{3}\right)\right]$ and $\mathrm{CuCl}$ as a cocatalyst. Various ratios of styrene derivatives $(2 \mathrm{a}-\mathrm{f})$ were applied to obtain a broad scope of bifunctional silsesquioxanes. As in the case of cross-metathesis, the desired products of the silylative coupling reaction $\left(7\left(\mathrm{R}^{2}-\mathrm{C}_{6} \mathrm{H}_{4}-\mathrm{CH}=\mathrm{CH}-\mathrm{SiMe}_{2}-\right)_{8-n}\left(\mathrm{R}^{1}-\mathrm{C}_{6} \mathrm{H}_{4}-\mathrm{CH}=\mathrm{CH}-\mathrm{SiMe}_{2}-{ }_{n} \mathrm{Si}_{8} \mathrm{O}_{12}\right)\right)$ can be synthesized in a one-pot manner, in two-step consecutive processes, without decreasing the effectiveness and isolation yields (Scheme 4).

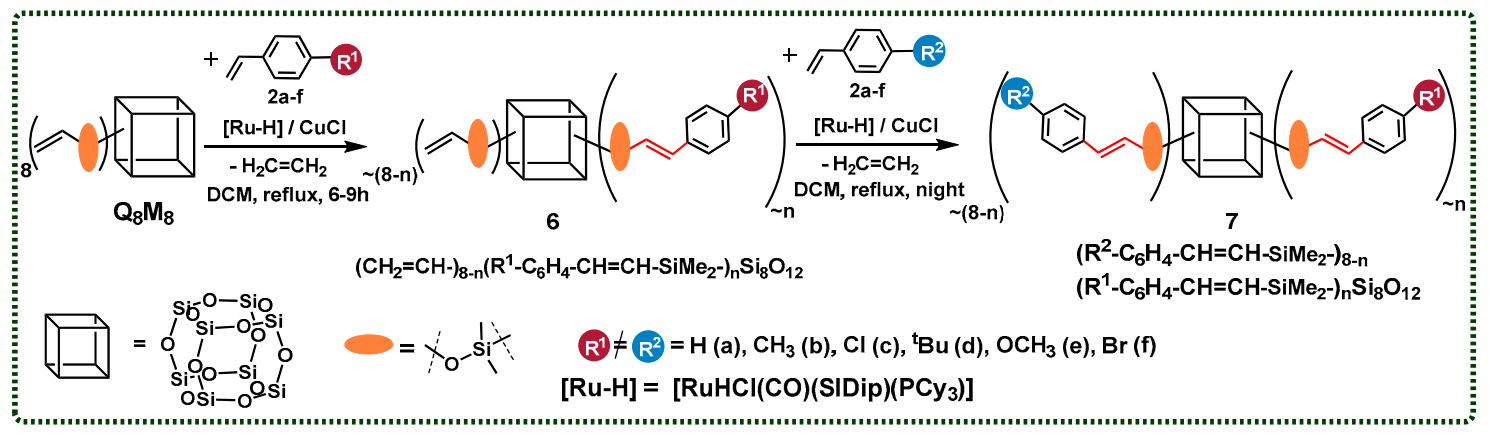

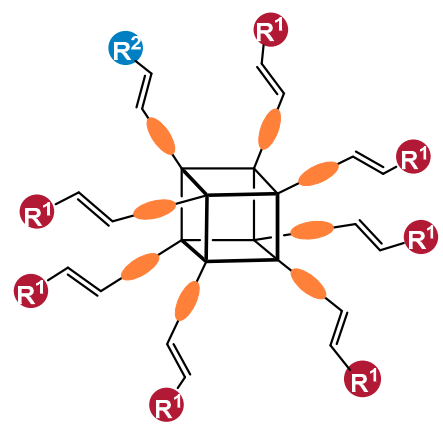

$\mathrm{n}=7 ; \mathbf{6 b}_{\sim 7} \quad \mathrm{R}^{1}=\mathrm{C}_{6} \mathrm{H}_{4}-\mathrm{Me}, \mathrm{R}^{2}=\mathrm{H}$

$\mathrm{n}=7 ; \mathbf{7 e} \mathbf{e}_{\sim 7} \mathbf{a}_{\sim 1} \mathrm{R}^{1}=\mathrm{C}_{6} \mathrm{H}_{4}-\mathrm{OMe}, \mathrm{R}^{2}=\mathrm{C}_{6} \mathrm{H}_{5}$

$\mathrm{n}=7 ; \mathbf{7} \mathbf{b}_{\sim 7} \mathbf{f}_{\sim \mathbf{1}} \mathrm{R}^{1}=\mathrm{C}_{6} \mathrm{H}_{4}-\mathrm{Me}, \mathrm{R}^{2}=\mathrm{C}_{6} \mathrm{H}_{4}-\mathrm{Br}$

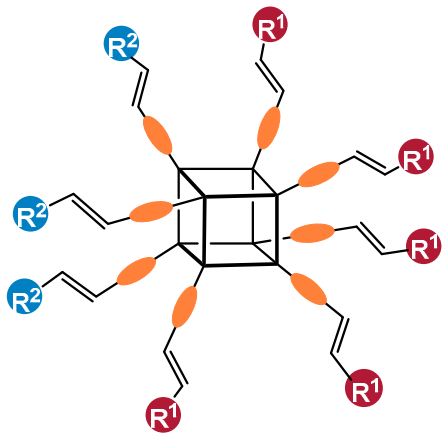

$\mathrm{n}=5 ; \mathbf{e}_{\sim 5} \quad \mathrm{R}^{1}=\mathrm{C}_{6} \mathrm{H}_{4}-\mathrm{OMe}, \mathrm{R}^{2}=\mathrm{H}$

$\mathrm{n}=5 ; \mathbf{7} \mathbf{b}_{\sim 5} \mathbf{c}_{\sim \mathbf{3}} \mathrm{R}^{1}=\mathrm{C}_{6} \mathrm{H}_{4}-\mathrm{Me}, \mathrm{R}^{2}=\mathrm{C}_{6} \mathrm{H}_{4}-\mathrm{Cl}$

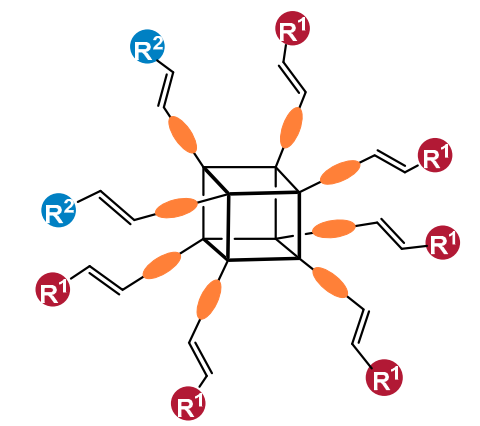

$\mathrm{n}=6 ; \mathbf{7} \mathbf{e}_{-\mathbf{6}} \mathbf{a}_{\sim 2} \mathrm{R}^{1}=\mathrm{C}_{6} \mathrm{H}_{4}-\mathrm{OMe}, \mathrm{R}^{2}=\mathrm{C}_{6} \mathrm{H}_{5}$

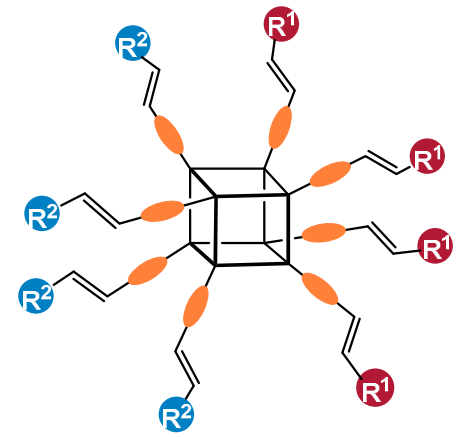

$\mathrm{n}=4 ; \mathbf{7} \mathbf{e}_{\sim 4} \mathbf{c}_{\sim \mathbf{4}} \mathrm{R}^{1}=\mathrm{C}_{6} \mathrm{H}_{4}-\mathrm{OMe}, \mathrm{R}^{2}=\mathrm{C}_{6} \mathrm{H}_{4}-\mathrm{Cl}$

Scheme 4. Two-step functionalization of octakis(dimethylvinylsilyloxy)silsesquioxane via silylative coupling, resulting in the formation of $6\left(\mathrm{CH}_{2}=\mathrm{CH}-\mathrm{SiMe}_{2}-\right)_{8-n}\left(\mathrm{R}^{1}-\mathrm{C}_{6} \mathrm{H}_{4}-\mathrm{CH}=\mathrm{CH}-\mathrm{SiMe}_{2}-\right)_{n} \mathrm{Si}_{8} \mathrm{O}_{12}$ and $\left.7\left(\mathrm{R}^{2}-\mathrm{C}_{6} \mathrm{H}_{4}-\mathrm{CH}=\mathrm{CH}-\mathrm{SiMe}_{2}-\right)_{8-\mathrm{n}}\left(\mathrm{R}^{1}-\mathrm{C}_{6} \mathrm{H}_{4}-\mathrm{CH}=\mathrm{CH}-\mathrm{SiMe}_{2}-\right)_{n} \mathrm{Si}_{8} \mathrm{O}_{12}\right)$. Reaction conditions: dichloromethane (DCM), $[\mathrm{RuHCl}(\mathrm{CO})(\mathrm{SIDip})(\mathrm{PCy} 3)] / \mathrm{CuCl},[\mathrm{Ru}]:[\mathrm{Cu}]=1: 5,[\mathrm{Ru}]=1.00 \mathrm{~mol} \%$, reflux, argon. The molecules designed to be obtained by the reaction's stoichiometry are presented. 
In addition, to clarify the results' demonstration, the products of the desired value of substitution (designated by the applied reagents' stoichiometry) were shown here (Scheme 4) (in one constitutional isomer for each structure).

Analogically, in each example, a $>99 \%$ conversion of $\mathrm{Q}_{8} \mathrm{M}_{8}$ was proven by ${ }^{1} \mathrm{H}$ NMR. The formation of the unsymmetrical products 7 with an exclusive $(E)$-stereochemistry around newly formed $\mathrm{Si}-\mathrm{HC}=\mathrm{CH}-\mathrm{Ar}$ double bonds was obtained (confirmed on the basis of ${ }^{1} \mathrm{H}$ NMR and $J_{H H}$ calculated at ca. $19 \mathrm{~Hz}$ ). A competitive polymerization of the styrene monomers was never observed. Furthermore, in this case, the statistical substitution of the tested substrates (2a-f) was observed, which was confirmed via MALDI-TOF analysis. An exemplary spectrum of the reaction mixture $\left(\mathrm{Me}-\mathrm{C}_{6} \mathrm{H}_{4}-\mathrm{CH}=\mathrm{CH}-\mathrm{SiMe}_{2}-\right)_{8-\mathrm{n}}\left(\mathrm{Cl}-\mathrm{C}_{6} \mathrm{H}_{5}-\mathrm{CH}=\mathrm{CH}-\mathrm{SiMe}_{2}-\right)_{\mathrm{n}} \mathrm{Si}_{8} \mathrm{O}_{12}$, designated for $\mathrm{n}=3\left(7 \mathrm{~b}_{5} \mathrm{C}_{3}\right)$, is presented in Figure 3.

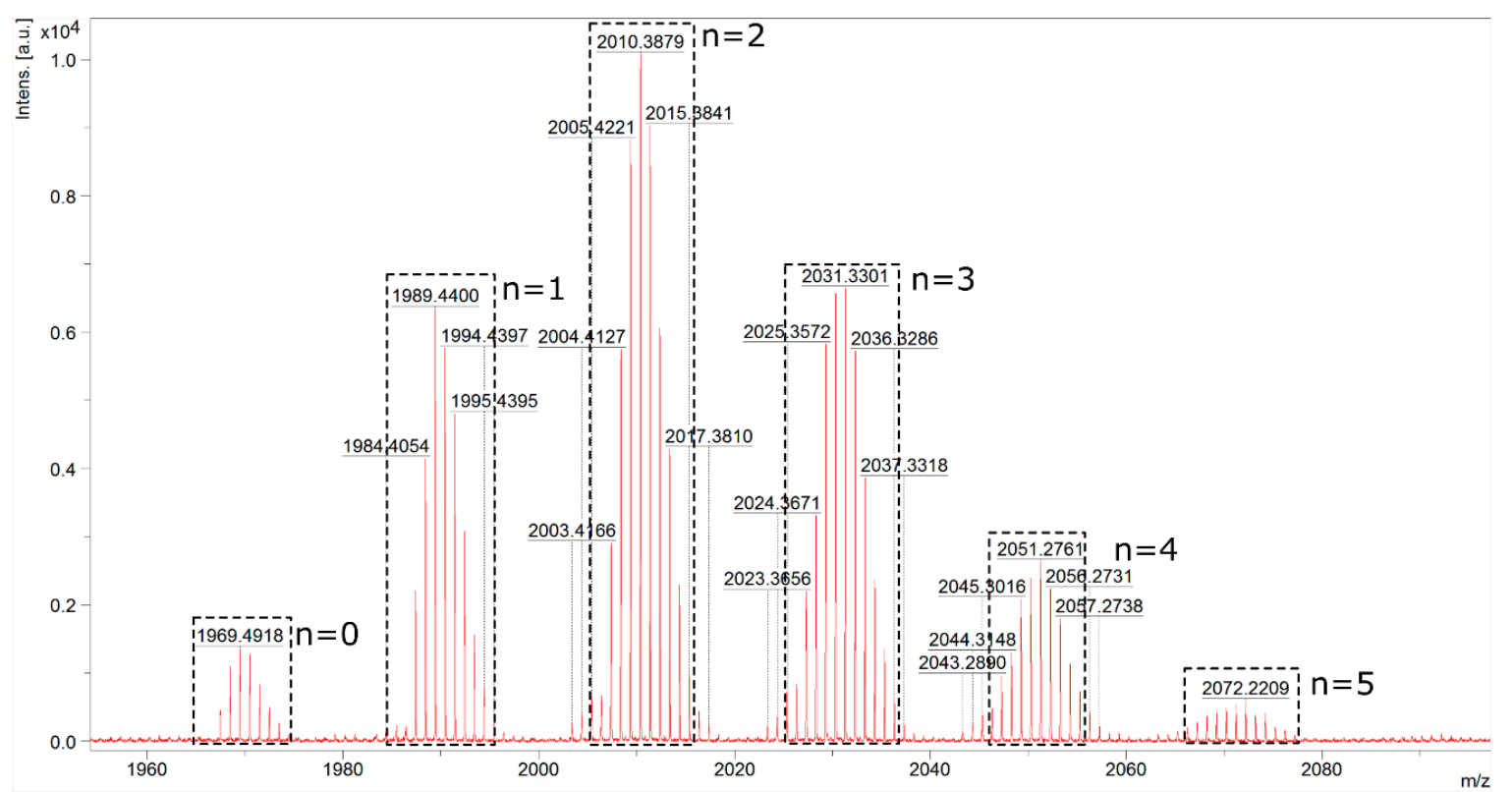

Figure 3. MALDI-TOF of the reaction mixture $\left(\mathrm{Me}-\mathrm{C}_{6} \mathrm{H}_{4}-\mathrm{CH}=\mathrm{CH}-\mathrm{SiMe}_{2}-\right)_{8-\mathrm{n}}\left(\mathrm{Cl}-\mathrm{C}_{6} \mathrm{H}_{5}-\mathrm{CH}=\mathrm{CH}-\mathrm{SiMe}_{2}-{ }_{n} \mathrm{Si}_{8} \mathrm{O}_{12}\right.$ (where $\mathrm{n}=0-5$ ) of the designated $7 \mathrm{~b}_{5} \mathrm{c}_{3}$.

The analysis confirmed the statistical distribution of two types of styrene moieties ( $2 b$ and $2 c)$ attached to the Si-O-Si core in the tested sample. The masses observed in the spectra came from sodiated silsesquioxanes molecules. The three most abundant compounds are presented in Figure 4 with their molecular weights.
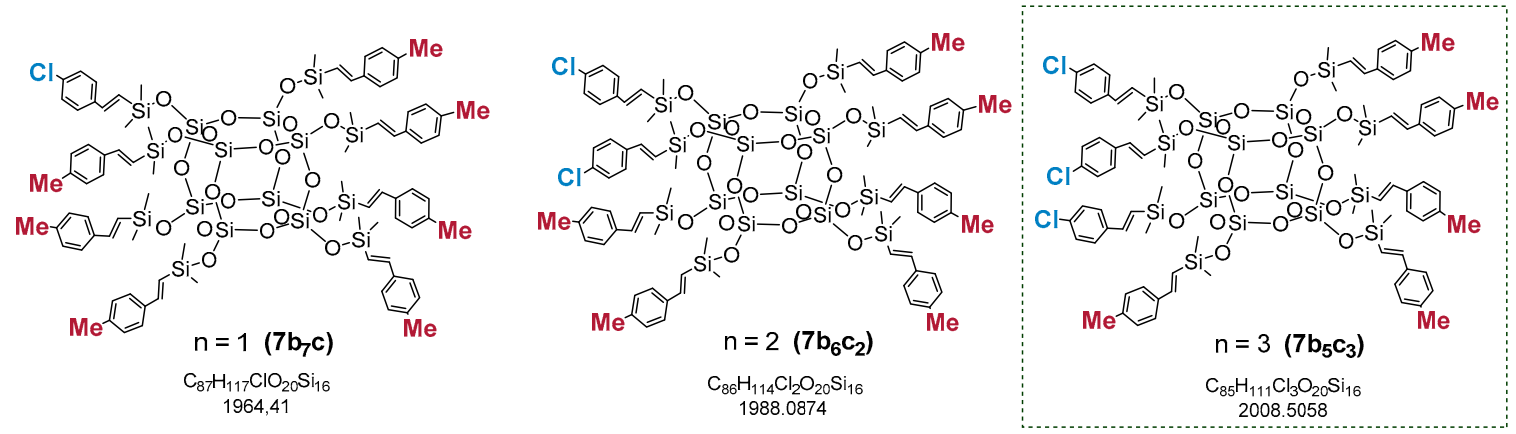

Figure 4. Possible structures derived from statistical substitution and the most abundant compounds in the reaction mixture of $\left(\mathrm{Me}-\mathrm{C}_{6} \mathrm{H}_{4}-\mathrm{CH}=\mathrm{CH}-\mathrm{SiMe}_{2}-\right)_{8-\mathrm{n}}\left(\mathrm{Cl}-\mathrm{C}_{6} \mathrm{H}_{5}-\mathrm{CH}=\mathrm{CH}-\mathrm{SiMe}_{2}-\right)_{n} \mathrm{Si}_{8} \mathrm{O}_{12}$ (where $\mathrm{n}=1,2,3) 7 \mathrm{~b}_{5} \mathrm{c}_{3}$, analyzed by MALDI-TOF. 
The calculated masses of the sodiated molecules of the respective molecules are: $\mathrm{C}_{87} \mathrm{H}_{117} \mathrm{ClO}_{20} \mathrm{Si}_{16} \mathrm{Na}\left(\mathrm{n}=1,7 \mathrm{~b}_{7} \mathrm{c}_{1}\right)-1987.40, \mathrm{C}_{86} \mathrm{H}_{114} \mathrm{Cl}_{2} \mathrm{O}_{20} \mathrm{Si}_{16} \mathrm{Na}\left(\mathrm{n}=2,7 \mathrm{~b}_{6} \mathrm{C}_{2}\right)-2007.35$ and $\mathrm{C}_{85} \mathrm{H}_{111} \mathrm{Cl}_{3} \mathrm{O}_{20} \mathrm{Si}_{16} \mathrm{Na}\left(\mathrm{n}=3,7 \mathrm{~b}_{5} \mathrm{c}_{3}\right)$-2027.29. The MALDI-TOF spectrum presented in Figure 3 shows the statistical distribution of bifunctional SQs, with the most intensive signal corresponding to a $2: 6$ substitution of the styrenes moieties ( $2 \mathrm{~b}$ and $2 \mathrm{c}$ ) used in the reaction. The products (7) were fully characterized by ${ }^{1} \mathrm{H},{ }^{13} \mathrm{C}$ and ${ }^{29} \mathrm{Si}$ NMR to confirm their structures, and the spectra are available in (Electronic Supporting Information) ESI (see Supplementary Materials).

The statistical distribution of the functional groups around the SQ's core was observed in every sample that was tested by MALDI-TOF analysis, but generally with the presence of the product with the desired styryl moieties' ratio in the majority, designated in the reaction stoichiometry. This confirms the fact that the reaction stoichiometry affects the ratio of the functional groups attached to the inorganic core. The presence of all substitution products and their respective ratio in each sample was presented in ESI. The observation of the presence of products with the statistical distribution of the functional moieties is not surprising, due to previous scientific reports that prove that the control of precise vertices' functionalization may usually be problematic $[7,8,12,28]$.

\section{Conclusions}

To conclude, we described the synthesis and characterization of twenty different bifunctional silsesquioxanes containing various 4 -substituted styryl groups. The analysis of ${ }^{1} \mathrm{H}$ NMR spectra proved the formation of $\mathrm{C}=\mathrm{C}$ bonds with an $E$ geometry, and MALDI-TOF showed the statistical distribution of compounds with two functional groups in 1:7, 2:6, 3:5 and 4:4 ratios, but with the highest abundance of the desired form being controlled by the reaction conditions and reagents' stoichiometry. A further modification of the obtained compounds can lead to multibranched molecules and find application in the synthesis of dendrimers, star-shaped polymers or hydrophobic agents. Despite the statistical substitution and arrangement of the functional groups in the $\mathrm{Si}-\mathrm{O}-\mathrm{Si}$, the resulting structures, especially in the case of partially substituted bromostyryl- and vinyl- derivatives, seem to be very interesting starting materials for further modifications.

Supplementary Materials: The following are available online at http://www.mdpi.com/1996-1944/13/18/3966/s1, Figures S1-S64: ${ }^{1} \mathrm{H},{ }^{13} \mathrm{C},{ }^{29} \mathrm{Si}$ NMR and MALDI-TOF spectra of obtained compounds.

Author Contributions: Conceptualization, P.Ż., B.D. and B.M.; methodology, P.Ż.; formal analysis, M.B.; investigation, M.B., P.Ż. and B.D.; resources, M.B., P.Ż. and B.D.; writing-original draft preparation, M.B.; writing-review and editing, P.Ż. and B.D.; writing, visualization, P.Ż.; supervision and project administration, A.S.; funding acquisition, P.Ż. and B.D. All authors have read and agreed to the published version of the manuscript.

Funding: The authors gratefully acknowledge the financial support from Foundation for Polish Science co-financed by the European Union under the European Regional Development Fund (P.Ż. project No. POMOST/2012-6/14) and from National Science Centre of Poland (B.D. project OPUS DEC-2016/23/B/ST5/00201).

Conflicts of Interest: The authors declare no conflict of interest.

\section{References}

1. Cordes, D.B.; Lickiss, P.D.; Rataboul, F. Recent developments in the chemistry of cubic polyhedral oligosilsesquioxanes. Chem. Rev. 2010, 110, 2081-2173. [CrossRef] [PubMed]

2. Chen, F.; Lin, F.; Zhang, Q.; Cai, R.; Wu, Y.; Ma, X. Polyhedral Oligomeric Silsesquioxane Hybrid Polymers: Well-Defined Architectural Design and Potential Functional Applications. Macromol. Rapid Commun. 2019, 40, 1900101. [CrossRef] [PubMed]

3. Wang, D.; Sun, R.; Feng, S.; Li, W.; Liu, H. Retrieving the original appearance of polyhedral oligomeric silsesquioxane-based porous polymers. Polymer 2017, 130, 218-229. [CrossRef]

4. Ge, M.; Liu, H. Fluorine-Containing Silsesquioxane-Based Hybrid Porous Polymers Mediated by Bases and Their Use in Water Remediation. Chem. A Eur. J. 2018, 24, 2224-2231. [CrossRef] [PubMed] 
5. Sun, R.; Feng, S.; Wang, D.; Liu, H. Fluorescence-Tuned Silicone Elastomers for Multicolored Ultraviolet Light-Emitting Diodes: Realizing the Processability of Polyhedral Oligomeric Silsesquioxane-Based Hybrid Porous Polymers. Chem. Mater. 2018, 30, 6370-6376. [CrossRef]

6. Asuncion, M.Z.; Roll, M.F.; Laine, R.M. Octaalkynylsilsesquioxanes, Nano Sea Urchin Molecular Building Blocks for 3-D-Nanostructures. Macromolecules 2008, 41, 8047-8052. [CrossRef]

7. Walczak, M.; Januszewski, R.; Dutkiewicz, M.; Franczyk, A.; Marciniec, B. A facile approach for the synthesis of novel silsesquioxanes with mixed functional groups. New J. Chem. 2019, 43, 18141-18145. [CrossRef]

8. Walczak, M.; Franczyk, A.; Dutkiewicz, M.; Marciniec, B. Synthesis of Bifunctional Silsesquioxanes (RSiMe2O) 4(R'SiMe2O) 4Si8O12 via Hydrosilylation of Alkenes. Organometallics 2019, 38, 3018-3024. [CrossRef]

9. Franczyk, A.; Stefanowska, K.; Dutkiewicz, M.; Frąckowiak, D.; Marciniec, B. A highly selective synthesis of new alkenylsilsesquioxanes by hydrosilylation of alkynes. Dalton Trans. 2017, 46, 158-164. [CrossRef]

10. Dutkiewicz, M.; MacIejewski, H.; Marciniec, B.; Karasiewicz, J. New fluorocarbofunctional spherosilicates: Synthesis and characterization. Organometallics 2011, 30, 2149-2153. [CrossRef]

11. Grzelak, M.; Januszewski, R.; Marciniec, B. Synthesis and Hydrosilylation of Vinyl-Substituted Open-Cage Silsesquioxanes with Phenylsilanes: Regioselective Synthesis of Trifunctional Silsesquioxanes. Inorg. Chem. 2020, 59, 7830-7840. [CrossRef] [PubMed]

12. Grzelak, M.M.; Marciniec, B. Synthesis of bifunctional silsesquioxanes and spherosilicates with organogermyl functionalities. Chem. Asian J. 2020, 15, 2437-2441. [CrossRef] [PubMed]

13. Stefanowska, K.; Franczyk, A.; Szyling, J.; Walkowiak, J. Synthesis of Functional 3-Buten-1-ynes and 1,3-Butadienes with Silsesquioxane Moiety via Hydrosilylation of 1,3-Diynes. ChemCatChem 2019, 11, 4848-4853. [CrossRef]

14. Walczak, M.; Januszewski, R.; Franczyk, A.; Marciniec, B. Synthesis of monofunctionalized POSS through hydrosilylation. J. Organomet. Chem. 2018, 872, 73-78. [CrossRef]

15. Walczak, M.; Stefanowska, K.; Franczyk, A.; Walkowiak, J.; Wawrzyńczak, A.; Marciniec, B. Hydrosilylation of alkenes and alkynes with silsesquioxane (HSiMe2O)(i-Bu)7Si8O12 catalyzed by Pt supported on a styrene-divinylbenzene copolymer. J. Catal. 2018, 367, 1-6. [CrossRef]

16. Żak, P.; Pietraszuk, C. Application of olefin metathesis in the synthesis of functionalized polyhedral oligomeric silsesquioxanes (POSS) and POSS-containing polymeric materials. Beilstein J. Org. Chem. 2019, 15, 310-332. [CrossRef]

17. Zak, P.; Marciniec, B.; Majchrzak, M.; Pietraszuk, C. Highly effective synthesis of vinylfunctionalised cubic silsesquioxanes. J. Organomet. Chem. 2011, 696, 887-891. [CrossRef]

18. Sulaiman, S.; Bhaskar, A.; Zhang, J.; Guda, R.; Goodson, T.; Laine, R.M. Molecules with perfect cubic symmetry as nanobuilding blocks for 3-D assemblies. Elaboration of octavinylsilsesquioxane. Unusual luminescence shifts may indicate extended conjugation involving the silsesquioxane core. Chem. Mater. 2008, 20, 5563-5573. [CrossRef]

19. Cheng, G.; Vautravers, N.R.; Morris, R.E.; Cole-Hamilton, D.J. Synthesis of functional cubes from octavinylsilsesquioxane (OVS). Org. Biomol. Chem. 2008, 6, 4662-4667. [CrossRef]

20. Zak, P.; Pietraszuk, C.; Marciniec, B.; Spólnik, B.; Danikiewicz, W. Efficient functionalisation of cubic monovinylsilsesquioxanes via cross-metathesis and silylative coupling with olefins in the presence of ruthenium complexes. Adv. Synth. Catal. 2009, 351, 2675-2682. [CrossRef]

21. Kaźmierczak, J.; Kuciński, K.; Hreczycho, G. Highly Efficient Catalytic Route for the Synthesis of Functionalized Silsesquioxanes. Inorg. Chem. 2017, 56, 9337-9342. [CrossRef] [PubMed]

22. Kaźmierczak, J.; Hreczycho, G. Nafion as effective and selective heterogeneous catalytic system in O-metalation of silanols and POSS silanols. J. Catal. 2018, 367, 95-103. [CrossRef]

23. Du, Y.; Liu, H. Cage-like silsesquioxanes-based hybrid materials. Dalton Trans. 2020, 49, 5396-5405. [CrossRef] [PubMed]

24. Dudziec, B.; Zak, P.; Marciniec, B. Synthetic routes to silsesquioxane-based systems as photoactive materials and their precursors. Polymers 2019, 11, 504. [CrossRef] [PubMed]

25. Hartmann-Thompson, C. Applications of Polyhedral Oligomeric Silsesquioxanes; Springer: Berlin/Heidelberg, Germany, 2011; ISBN 9789048137862.

26. Kalia, S.; Pielichowski, K. Polymer/POSS Nanocomposites and Hybrid Materials; Springer: Berlin/Heidelberg, Germany, 2018; ISBN 978-3-030-02326-3. 
27. Sellinger, A.; Laine, R.M. Silsesquioxanes as synthetic platforms. Thermally curable and photocurable inorganic/organic hybrids. Macromolecules 1996, 29, 2327-2330. [CrossRef]

28. Sellinger, A.; Tamaki, R.; Laine, R.M.; Ueno, K.; Tanabe, H.; Williams, E.; Jabbour, G.E. Heck coupling of haloaromatics with octavinylsilsesquioxane: Solution processable nanocomposites for application in electroluminescent devices. Chem. Commun. 2005, 29, 3700-3702. [CrossRef]

29. Wang, S.; Guang, S.; Xu, H.; Ke, F. Controllable preparation and properties of active functional hybrid materials with different chromophores. RSC Adv. 2015, 5, 1070-1078. [CrossRef]

30. Zhao, G.; Gong, X.; Wei, G.; Liu, Q.; Guang, S.; Zhang, F.; Ke, F.; Xu, H. Facile preparation and properties of polyhedral oligomeric silsesquioxane (POSS) nano-hybrid materials with disaggregation effect. Mater. Sci. Eng. B 2019, 246, 136-142. [CrossRef]

31. Chanmungkalakul, S.; Ervithayasuporn, V.; Boonkitti, P.; Phuekphong, A.; Prigyai, N.; Kladsomboon, S.; Kiatkamjornwong, S. Anion identification using silsesquioxane cages. Chem. Sci. 2018, 9, 7753-7765. [CrossRef]

32. Oguri, N.; Egawa, Y.; Takeda, N.; Unno, M. Janus-Cube Octasilsesquioxane: Facile Synthesis and Structure Elucidation. Angew. Chem. Int. Ed. 2016, 55, 1-5.

33. Takeuchi, H.; Konno, T.; Mori, H. Synthesis of multifunctional silsesquioxane nanoparticles with hydroxyl and polymerizable groups for UV-curable hybrid coating. React. Funct. Polym. 2017, 115, 43-52. [CrossRef]

34. Sasaki, Y.; Shibasaki, S.; Lo, C.T.; Nakabayashi, K.; Mori, H. Design and synthesis of multi-functional silsesquioxane nanoparticles having two distinct optoelectronic functionalities. Colloid Polym. Sci. 2018, 296, 1017-1028. [CrossRef]

35. Shibasaki, S.; Sasaki, Y.; Nakabayashi, K.; Mori, H. Synthesis and metal complexation of dual-functionalized silsesquioxane nanoparticles by sequential thiol-epoxy click and esterification reactions. React. Funct. Polym. 2016, 107, 11-19. [CrossRef]

36. Uchida, T.; Egawa, Y.; Adachi, T.; Oguri, N.; Kobayashi, M.; Kudo, T.; Takeda, N.; Unno, M.; Tanaka, R. Synthesis, Structures, and Thermal Properties of Symmetric and Janus "Lantern Cage" Siloxanes. Chem. A Eur. J. 2019, 25, 1683-1686. [CrossRef] [PubMed]

37. Han, S.Y.; Wang, X.M.; Shao, Y.; Guo, Q.Y.; Li, Y.; Zhang, W. Bin Janus POSS Based on Mixed [2:6] Octakis-Adduct Regioisomers. Chem. A Eur. J. 2016, 22, 6397-6403. [CrossRef] [PubMed]

38. Feher, F.J.; Wyndham, K.D.; Baldwin, R.K.; Soulivong, D.; Lichtenhan, J.D.; Ziller, J.W. Methods for effecting monofunctionalization of $(\mathrm{CH} 2=\mathrm{CH}) 8 \mathrm{Si8O12}$. Chem. Commun. 1999, 14, 1289-1290. [CrossRef]

39. Wang, X.-M.; Guo, Q.-Y.; Han, S.-Y.; Wang, J.-Y.; Han, D.; Fu, Q.; Zhang, W. Bin Stochastic/Controlled Symmetry Breaking of the T 8-POSS Cages toward Multifunctional Regioisomeric Nanobuilding Blocks. Chem. A Eur. J. 2015, 21, 15246-15255. [CrossRef]

40. Blázquez-Moraleja, A.; Pérez-Ojeda, M.E.; Suárez, J.R.; Jimeno, M.L.; Chiara, J.L. Efficient multi-click approach to well-defined two-faced octasilsesquioxanes: The first perfect Janus nanocube. Chem. Commun. 2016, 52, 5792-5795. [CrossRef]

41. Wang, X.-M.; Shao, Y.; Xu, J.; Jin, X.; Shen, R.-H.; Jin, P.-F.; Shen, D.-W.; Wang, J.; Li, W.; He, J.; et al. Precision Synthesis and Distinct Assembly of Double-Chain Giant Surfactant Regioisomers. Macromolecules 2017, 50, 3943-3953. [CrossRef]

42. Pørez-ojeda, M.E.; Trastoy, B.; Rol, A.; Chiara, M.D.; Garcia-Moreno, I.; Chiara, J.L. Controlled Click-Assembly of Well-Defined Hetero-Bifunctional Cubic Silsesquioxanes and Their Application in Targeted Bioimaging. Chem. A Eur. J. 2013, 19, 6630-6640. [CrossRef]

43. Maciejewski, H.; Karasiewicz, J.; Dutkiewicz, M.; Marciniec, B. Hydrophobic Materials Based on Fluorocarbofunctional Spherosilicates. Silicon 2015, 7, 201-209. [CrossRef]

44. Tomaszewska, J.; Sterzyński, T.; Skórczewska, K. Effect of Polyhedral Oligomeric Silsesquioxanes Nanoparticles on Thermal and Mechanical Properties of Poly(vinyl chloride) Composite Materials. J. Vinyl Addit. Technol. 2019, 25, E48-E54. [CrossRef]

45. Przybylak, M.; Maciejewski, H.; Dutkiewicz, A. Preparation of highly hydrophobic cotton fabrics by modification with bifunctional silsesquioxanes in the sol-gel process. Appl. Surf. Sci. 2016, 387, 163-174. [CrossRef]

46. Ro, H.W.; Popova, V.; Krug, D.J.; Forster, A.M.; Laine, R.M.; Soles, C.L. Cubic silsesquioxanes as tunable high-performance coating materials. Appl. Organomet. Chem. 2013, 27, 652-659. [CrossRef] 
47. Ro, H.W.; Popova, V.; Chen, L.; Forster, A.M.; Ding, Y.; Alvine, K.J.; Krug, D.J.; Laine, R.M.; Soles, C.L. Cubic silsesquioxanes as a green, high-performance mold material for nanoimprint lithography. Adv. Mater. 2011, 23, 414-420. [CrossRef] [PubMed]

48. Chanmungkalakul, S.; Ervithayasuporn, V.; Hanprasit, S.; Masik, M.; Prigyai, N.; Kiatkamjornwong, S. Silsesquioxane cages as fluoride sensors. Chem. Commun. 2017, 53, 12108-12111. [CrossRef]

49. Han, D.; Wen, T.J.; Han, G.; Deng, Y.; Zhang, Q.; Fu, Q. Synthesis of Janus POSS star polymer and exploring its compatibilization behavior for PLLA/PCL polymer blends. Polymer 2018, 136, 84-91. [CrossRef]

50. Jin, P.F.; Shao, Y.; Yin, G.Z.; Yang, S.; He, J.; Ni, P.; Zhang, W. Bin Janus [3:5] Polystyrene-Polydimethylsiloxane Star Polymers with a Cubic Core. Macromolecules 2018, 51, 419-427. [CrossRef]

51. Olivero, F.; Renò, F.; Carniato, F.; Rizzi, M.; Cannas, M.; Marchese, L. A novel luminescent bifunctional POSS as a molecular platform for biomedical applications. Dalton Trans. 2012, 41,7467-7473. [CrossRef]

52. Laine, R.M.; Roll, M.; Asuncion, M.; Sulaiman, S.; Popova, V.; Bartz, D.; Krug, D.J.; Mutin, P.H. Perfect and nearly perfect silsesquioxane (SQs) nanoconstruction sites and Janus SQs. J. Sol Gel Sci. Technol. 2008, 46, 335-347. [CrossRef]

53. Zak, P.; Delaude, L.; Dudziec, B.; Marciniec, B. N-Heterocyclic carbene-based ruthenium-hydride catalysts for the synthesis of unsymmetrically functionalized double-decker silsesquioxanes. Chem. Commun. 2018, 54, 4306-4309. [CrossRef] [PubMed]

54. Zak, P.; Dudziec, B.; Kubicki, M.; Marciniec, B. Silylative coupling versus metathesis—Efficient methods for the synthesis of difunctionalized double-decker silsesquioxane derivatives. Chem. A Eur. J. 2014, 20, 9387-9393. [CrossRef] [PubMed]

55. Zak, P.; Majchrzak, M.; Wilkowski, G.; Dudziec, B.; Dutkiewicz, M.; Marciniec, B. Synthesis and characterization of functionalized molecular and macromolecular double-decker silsesquioxane systems. RSC Adv. 2016, 6, 10054-10063. [CrossRef]

56. Yi, C.S.; Lee, D.W.; Chen, Y. Hydrovinylation and [2+2] Cycloaddition Reactions of Alkynes and Alkenes Catalyzed by a Well-Defined Cationic Ruthenium—Alkylidene Complex. Organometallics 1999, 18, 1997-1999. [CrossRef]

57. Bassindale, A.R.; Liu, Z.; MacKinnon, I.A.; Taylor, P.G.; Yang, Y.; Light, M.E.; Horton, P.N.; Hursthouse, M.B. A higher yielding route for $\mathrm{T} 8$ silsesquioxane cages and $\mathrm{X}$-ray crystal structures of some novel spherosilicates. Dalton Trans. 2003, 14, 2945-2949. [CrossRef]

58. Hurkes, N.; Bruhn, C.; Belaj, F.; Pietschnig, R. Silanetriols as powerful starting materials for selective condensation to bulky POSS cages. Organometallics 2014, 33, 7299-7306. [CrossRef] 